\title{
Acardiac Acephalus Twin Pregnancy
}

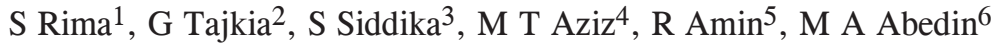

\begin{abstract}
Occurrence of acardiac twin is due to twin reversed arterial perfusion sequence (TRAP) occurring early in embryogenesis. There is vascular communication between the twins in monozygotic twins. The vascular communication in acardiac twin is different, in that, the acardiac twin receives blood supply from other twin pump through umbilical artery. The blood in the umbilical artery is mostly deoxygenated. Hence it leads to secondary organ atrophy. Upper body does not develop at all, hence missing heart and head. All the blood supply to the acardiac twin is derived from the pump twin. The acardiac twin develops only lower part of the body or just a mass of tissue. Hence, the mortality for acardiac twin is $100 \%$.
\end{abstract}

Key Words: Acardiac twin, TRAP, monozygotic twin, umbilical artery.

\section{Introduction}

Acardiac twining also referred to as the twin reversed arterial perfusion sequence (TRAP) represents an extreme manifestation of the twin transfusion syndrome ${ }^{1}$. The acardiac twin is transfused $b$ y the normal co twin by means of reversal of circulation through large vein to vein and artery to artery anastomosis and has no direct communication with placenta. The acardiac twin presents with many bizarre anomalies thought to be due to low oxygen tension and dramatic alterations in the fetal physiology ${ }^{2}$.

\section{Case Report}

A 27-year-old gravida 2 was referred to outpatient department (OPD) of Anwer Khan Modern Medical College Hospital with suspected twin pregnancy at $22+$ weeks of gestation. Examination revealed a term-sized gravid uterus with an increased amount of amniotic fluid. Fetal heart sounds could not be localized.

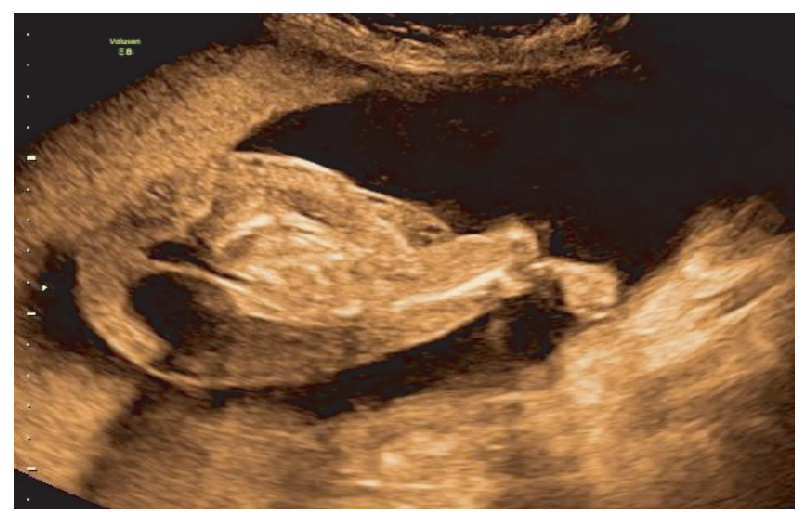

Fig 1: Acardiac twin with absent fetal head and upper limb with cystichygroma.

Ultrasonography revealed a monozygotic twin pregnancy with 1 acardiac fetus and 1 normal fetus with polyhydramnios (amniotic fluid index : $49.20 \mathrm{cc}$ ) with single placenta. Other investigations included complete blood count, serum creatinine, Chest X-ray, ECG, urinalysis, syphilis screening, and blood glucose measurement.

$1 *$ Dr. Shamim Rima, Assistant Professor, Dept. of Radiology \& Imaging, Anwer Khan Modern Medical College \& Hospital

${ }^{2}$ Dr. Gule Tajkia, Assistant Professor, Department of Paediatrics, Anwer Khan Modern Medical College \& Hospital

${ }^{3}$ Dr. Sharmin Siddika, Assistant Professor, Department of Obstetrics \& Gynaecology. Anwer Khan Modern Medical College \& Hospital

${ }^{4}$ Dr. Md. Tarik Aziz, Assistant Registrar, Department of Surgery, Anwer Khan Modern Medical College \& Hospital

${ }_{5}^{5}$ r. Rumana Amin, Medical Officer, Department of Paediatrics, Anwer Khan Modern Medical College \& Hospital

${ }^{6}$ Dr. M Afsar Abedin, Lecturer, Department of Anatomy, Anwer Khan Modern Medical College \& Hospital

*Corresponding Author

Date of submission: 08.08.2018 Date of acceptance: 24.10 .2018

AKMMC J 2019; 10(1) : 89-91 


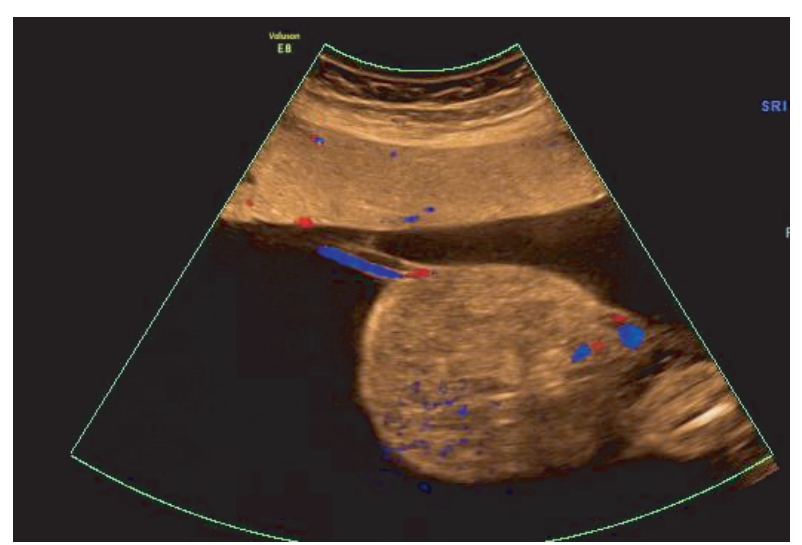

Fig 2: Acardiac twin with short umbilical cord.

At $24^{\text {th }}$ weeks of gestation spontaneous abortion occurred due to severe polyhydramnios. A premature fetus with normal morphology and a malformed acardiac fetus were delivered. Acardiac twin do not had CNS, cervical spine \& upper limb; under developed chest, abdominal organ, fused lower limb with clubbing of both feet.

\section{Discussion}

Acardiac twinning or TRAP sequence is a rare congenital anomaly of monozygotic multiple pregnancy due to abnormal placental anastomosis characterized by formation of a malformed fetus with an absent or rudimentary heart (acardius) along with other structures. Prevalence of multiple pregnancies is $1.5 \%$ of all pregnancies and TRAP sequence is 1 per 35,000 births $^{3}$. Acardiac fetuses were first described by Benedetti in 1533. Twin reversed arterial perfusion was defined by Greenwald in 1942. It is classified according to the degree of cephalic and truncal mal-development; The first type is Acardius acephalus, where no cephalic structures present (head \& upper extremities are lacking). It is most common variety. The second is Acardius acephalus where some cranial structure and neural tissue or brain tissue is present. The body and extremities are also developed. It is highly developed form. The third is Acardius acormus with cephalic structure but no truncal structures are present.i.e. Head without a body. The umbilical cord is attached to the head. It is rarest form of Acardia.The fourth type is Acardius amorphous with no distinguishable cephalic or truncal structure. It is least developed and not recognizable as human form with minimal development. This differs from Teratomas only by its attachment to an umbilical cord. It has been hypothesized that the TRAP sequence is caused by a large artery to artery placental shunt often accompanied by a vein to vein shunt. Within the single shared placenta, arterial perfusion pressure of the donor twin exceeds that of the recipient twin who thus receives reverse blood flow of deoxygenated arterial blood from its co-twin. This used blood reaches the recipient twin through its umbilical arteries and preferentially goes to its iliac vessels. Thus only the lower body is perfused and disrupted growth and development of the upper body results. An acardiac twin should be suspected in all monochorionic, malformed fetuses with cystic hygroma, generalized edema and an absent cardiac pulsation with a non-functioning heart. Ultrasonography finding of twins revealing discordant or grotesque malformation along with reverse flow in the umbilical artery is usually diagnostic of an acardiac twin. Vaginal scanning and color doppler sonography is useful to diagnose it. Such twin pregnancies can be accessed by serial ultrasonography. Total or partial absence of cranial vault, holoprosencephaly, absent facial structures, anophthalmia, microphthalmia, cleft lip, cleft palate, absent or rudimentary limbs, lungs, heart, liver and gallbladder, diaphragmatic defects, esophageal atresia, ventral wall defects, ascites, edema of skin and single umbilical artery are prominent features of recipient twin. Several different techniques have been used to treat TRAP sequence by interrupting the connection between the acardiac twin and the pump twin to increase the chances that the pump twin will survive. These techniques include cord occlusion by embolization, ligation, laser photocoagulation, monopolar and bipolar diathermy. Intrafetal ablation has also been performed by alcohol injection, monopolar diathermy, interstitial laser, and radiofrequency ablation (RFA) ${ }^{11}$.

\section{Conclusion}

Diagnosis of acardiac twin can be made in the first trimester itself by USG and Doppler. Early diagnosis of chronicity of twin pregnancy helps in improving the survival of the pump twin. Prevention 
of preterm labor and diagnosing cardiac failure in the pump twin is very important. First line of treatment is by blocking the vessel of acardiac twin by radio frequency ablation by ultrasound guidance. Treatment at appropriate time improves the survival of the pump twin by $95 \%$ with an average age at delivery between 36 and 37 weeks.

\section{References}

1. Athwal S, Millard K, Lakhoo K. Twin reversed arterial perfusion (TRAP) Sequence in association with VACTERL association: A case report. J MedCase Rep 2010 22; 4: 411.

2. Chanthasenanont A, Pongrojpaw D. Acardiac twin. J Med Assoc Thai 2005; 88: 1721-4.

3. Dhall U, Kayalvizhi I, Magu S. Acardius Acephalus Monster - A case report. J Anat Soc India. 2005; 54(1): 26-28.

4. Mohanty C, Mishra OP, Singh CP, et al. Acardiac Anomaly Spectrum. Tetralogy 2000; 62: 356-9.

5. Napolitano FD. Schreiber. The acardiac moster: a review of the word literature and presentation of two cases. American Journal of Obstetrics Gynaecology 1960; 80: 582-589.

6. Blaicher W, Repa C, Schaller A. Acardiac twin pregnancy: associated with trisomy 2: case report. Hum Reprod., 2000; 15(2): 474-5.
7. Cunningham FG, Leveno KJ, Bloom SL, Hauth JC, Rouse DJ, Spong CY. Williams Obstetrics, $23^{\text {rd }}$ edition, McGraw Hill, New York, 2010, p. 872. Hecher K, Lewi L, Huber GR, et al. Twin reversed arterial perfusion: fetoscopic laser coagulation of placental anastomoses or the umbilical cord. Ultrasound in Obstetrics and Gynecology 2006; 28: 688-691, 2006.

8. Donnenfeld AE, van de Woestijne J, Craparo F, et al. The normal fetus of an acardiac twin pregnancy: Perinatal management based on echocardiographic and sonographic evaluation. Prenatal Diagnosis. 1991 Apr; 11(4): 235-44.

9. Simpson PC, Trudinger BJ, Walker A, et al. The intrauterine treatment of fetal cardiac failure in a twin pregnancy with an acardiac, acephalic monster. Am J Obstet Gynecol.1983 Dec 1; 147(7): 842-4

10. Quintero RA, Reich H, Puder KS, et al. Brief report: Umbilicalcord ligation of an acardiac twin by fetoscopy at 19 weeks of gestation. New Engl J Med. 1994 Feb 17; 330(7): 469-71.

11. Grab D, Schneider V, Keckstein J, et al. Twin acardiac outcome. Fetus 1992; 2(1): 110-11. 